\title{
The variability of dynamic coefficient of friction material in flexible packaging
}

\author{
Ivana Ljevak', Igor Zjakić², Dubravko Banić \\ ${ }^{1}$ Badel1862, Vlaška 116, Zagreb, Croatia \\ ${ }^{2}$ University of Zagreb, Faculty of Graphic Arts, Getaldićeva 2, Zagreb, Croatia \\ ${ }^{*}$ E-mail:
}

\begin{abstract}
Appropriate labeling and flexible packaging plays an important role on the today's demands. There is diverse possibilities especially related to polymeric materials. Flexible packaging means to consider options such as OPP (Oriented Polypropylene), PVC (Polyvinyl Chloride), OPS (Oriented Polystyrene), PET (Polyethylene Terephthalate) or all kind of self-adhensive paper and foil types. Special highlight are the "Shrink Sleeve" labels that meet the most demanding market challenges. Its capabilities are beneficial. Laminated packaging materials are functional. Both constitute protection and packaging capacity. Coefficient of friction is the value that serves to meet the standard of how the flexible packaging material will glide and move on the packaging machine. This research is focused on the optimum quality of the packaging production process to meet all the preconditions for implementation of the semifinished product packaging and to avoid difficulties and possible stoppages on the packaging machine itself.
\end{abstract}

Keywords: coefficient of friction, polymer materials, flexible packaging

\section{Introduction}

Flexible packaging, in its variety of forms, has been the fastest growing segment of the packaging industry. These packages may be formed from paper plastic, aluminum foil, or combinations of these materials. Plastics provide barrier, strength, and heat stability. An important attribute of flexible packaging is its ability to form thinner, lighter, more compact packages. Plastics may be used in single-layer materials, coextrusions, laminations, or coatings [1].

The coefficient of friction (COF) is the value measured to determine how flexible the polymeric packaging material will glide on the packaging machine, move or slide with difficulty or cause possible shortages. COF is measured on the inside and outside of the foil because both sides slide over the metal parts of the packaging machine depending on the pressure it might change its property.

Various packaging machines require different film properties [2]. Therefore, the film can show good results on a packaging machine while on the other is not an option. COF is a value that no producer of materials guarantees because it can not be fully controlled precisely because of the different specifications of packaging machines.

COF depends on the amount of Slip Additives in the material recipe. Special Slip Additives in the production of the material itself are affected by slippage, but after printing, cracking, cutting and any confectionery, friction changes due to the migration occurring within the printed, tear-off and wrapped foils for the tension that affects the layer to layer pressure. According to the amount of additives in the material migrating within the same COF, it shows different values. The COF standards are areas of slippage that do not cause problems in the sense of stoppage (creasing, bursting of materials, unwanted forming of weld) when packing on a packaging machine.

\section{Coefficient of friction}

The friction coefficient $(\mu)$ is the force that occurs on the touching surface of the two object 
when moving one object on the surface of the other object and which makes it difficult for the movement (dynamic friction force) or prevents motion (static friction force). Depending on the roughness and chemical composition of surfaces that touch, their moisture or lubricity, and how the body moves (the biggest factor of friction is the static, less friction factor gliding, the least friction factor rolling) [3]. The friction factor measurement unit moves between $0<1$.

The friction factor can be determined using a variable inclination slope so that the angle a is determined by which the object begins to measure roll down of the slope, $\mu=\tan \alpha$ [4].

Static coeficient of friction. The force increases linearly to a maximum which represents the static frictional force Fs. Measurements made at a high friction drag permit the dynamic coefficient of friction to be calculated, but not the static coefficient of friction. The static coefficient of friction $\mu$ s is given by the equation:

$\mu s=\frac{F s}{F p}$

where Fs is the static frictional force, expressed in newtons; Fp is the normal force exerted by the mass of the sled, expressed in newtons $(-1,90 \mathrm{~N})$.

Dynamic coefficient of friction. The frictional force acting during the sliding motion often differs from the constant value which would exist in an ideal situation due to secondary effects related to increasing path length.

The dynamic frictional force FD is the average force over the first $6 \mathrm{~cm}$ of movement after the start of relative movement between the surfaces in contact, neglecting the static force peak Fp. The dynamic coefficient of friction $\mu \mathrm{D}$ is calculated from the dynamic frictional force using the equation:

$\mu D=\frac{F D}{F p}$

where FD is the dynamic frictional force, expressed in newtons; Fp is the normal force exerted by the mass of the sled, expressed in newtons $(-1,96 \mathrm{~N})$.

The inertia of the mass of the sled induces an additional force at the start of the sled movement; thus the coefficient of friction differs from its true value by an amount $\Delta$ given by:
$\Delta=\frac{v}{g} \sqrt{\frac{D}{m}}$

where $\mathrm{v}$ is the speed of the sled relative to the table $(100 \mathrm{~mm} / \mathrm{min}) ; \mathrm{m}$ is the mass of the sled $(200 \mathrm{~g}) ; \mathrm{g}$ is the acceleration due to gravity $\left(9,810 \mathrm{~mm} / \mathrm{s}^{2}\right) ; \mathrm{D}$ is the friction drag $(2 \mathrm{~N} / \mathrm{cm}$ $=2 \times 10^{3} \mathrm{~g} / \mathrm{s}^{2}$ ).

Under this conditions, the overshoot of the coefficient of friction is 0,005 . In the worst case at a low coefficient of friction of 0,2 the overshoot equals an error of $2,5 \%$.

\section{Materials and methods}

The coefficient of friction on the packaging flexibles occurs on the inside and outside of the material, and as such is of great importance because it can reduce the efficiency of the packing machine. Flexographic printing proved to be such a useful technique in the packaging industry. One of the advancing segments of the packaging industry is its flexible packaging, with the flexible plastic component being the most prominent among them [6].

\subsection{Films and laminates}

Films are materials with a nominal thickness not exceeding $250 \mu \mathrm{m}$. Monofilms are homogeneous films made of one material. To manufacture a film for printing purposes, the following are primarily use PE, PP, PET, PVC, PA, PS, PC. Multilayer films are also called complex films and those obtained in the lamination process are called laminates. Laminates next to plastic films are one of the basic polymeric substrates. They are manufactured by combining two or more plastic films, or any combination of plastic films (PE, polyester, PP, cellulose, $\mathrm{PA}$ ), with aluminium film or paper products. Usually, it is from two to five layers. The materials are joined together by gluing, calendaring, or coextrusion. A proper selection of the individual layers of sometimes extremely different physicochemical properties and barrier properties makes it possible to obtain a material with almost any characteristics [7].

A method for determining the coefficients of starting and sliding friction of plastic films and sheeting when sliding over itself or other substances. The metod is intended to be used for 
non-sticky plastic film and sheeting of up to approximately $0,5 \mathrm{~mm}$ tickness.

This method serves primarily for quality control. It does not give a comprehesive assessment of the machinability on packaging or processing machines since other effects, electrostatic charges, air cushion, local rise of temperature and abrasion involved [8].

\section{Experimental part}

Materials used in this study are laminates which are used in food packaging duplex OPA/ $\mathrm{PE}$ and BOPP/PPmet, triplex PET/AL/PELD. Measurements were performed on 20 samples for each laminate on the outside and inside of the material.

Table 1. Technical characteristics of the materials BOPP/PPmet

\begin{tabular}{|l|l|l|l|}
\hline Characteristics & Standard ISO & Measure & Value \\
\hline Width & & $\mathrm{mm}$ & 527 \\
\hline Height & & $\mathrm{mm}$ & 300 \\
\hline Thickness & ISO 4593 & $\mu \mathrm{m}$ & $43-45$ \\
\hline Total grammar & ISO 536 & $\mathrm{~g} / \mathrm{m}^{2}$ & 42 \\
\hline Weld temperature & & ${ }^{\circ} \mathrm{C}$ & 115 \\
\hline
\end{tabular}

Table 2. Technical characteristics of the materials PET/ AL/PELD

\begin{tabular}{|l|l|l|l|}
\hline Characteristics & Standard ISO & Measure & Value \\
\hline Width & & $\mathrm{mm}$ & 340 \\
\hline Height & & $\mathrm{mm}$ & 130 \\
\hline Thickness & ISO 4593 & $\mu \mathrm{m}$ & $97-101$ \\
\hline Total grammar & ISO 536 & $\mathrm{~g} / \mathrm{m}^{2}$ & 111,68 \\
\hline Weld temperature & & ${ }^{\circ} \mathrm{C}$ & 118 \\
\hline
\end{tabular}

Table 3. Technical characteristics of the materials OPA/PE

\begin{tabular}{|l|l|l|l|}
\hline Characteristics & Standard ISO & Measure & Value \\
\hline Width & & $\mathrm{mm}$ & 220 \\
\hline Height & & $\mathrm{mm}$ & 1000 \\
\hline Thickness & ISO 4593 & $\mu \mathrm{m}$ & 90 \\
\hline $\begin{array}{l}\text { Gramatura uku- } \\
\text { pna }\end{array}$ & ISO 536 & $\mathrm{~g} / \mathrm{m}^{2}$ & 79,05 \\
\hline Weld temperature & & ${ }^{\circ} \mathrm{C}$ & 115 \\
\hline
\end{tabular}

The surface area of the material has a high impact on the coefficient of friction, so microscope Dino Lite obtained a detailed sample structure. Samples of lengths of $0,5 \mathrm{~cm}$ were taken for each material.

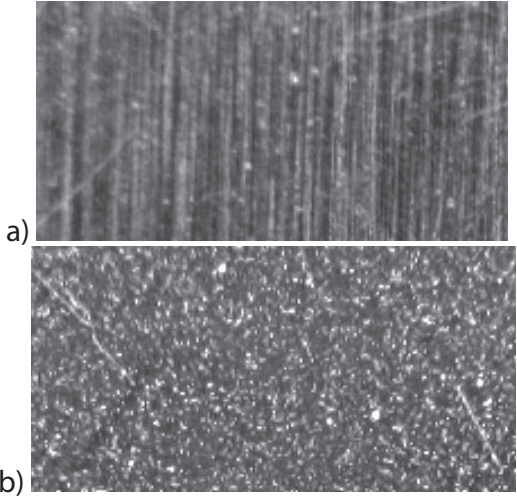

Figure 1. Structure of polymeric materials duplex and triplex a) BOPP/PPmet; b) PET/AL/PELD

Microscope analysis could not be performed on the duplex laminate OPA / PE on its structure and transparency of the material, due to reflection, where the surface could not obtain accurate spectrophotometric curve of the wavelength of the visible spectrum. Therefore, it made analysis reflection of gray tones, which are measured in the 0-255 level of grayness at the duplex BOPP / PP met and triplex PET / AL / LDPE in order to get a surface structure in the opposite direction of the pulling of the material to the finished product. Drawn curves show the values of gray tones on the material.

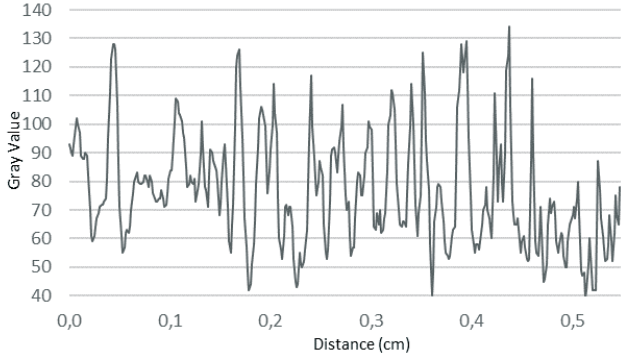

Figure 2. Representation of the gray tones in the material BOPP/PPmet

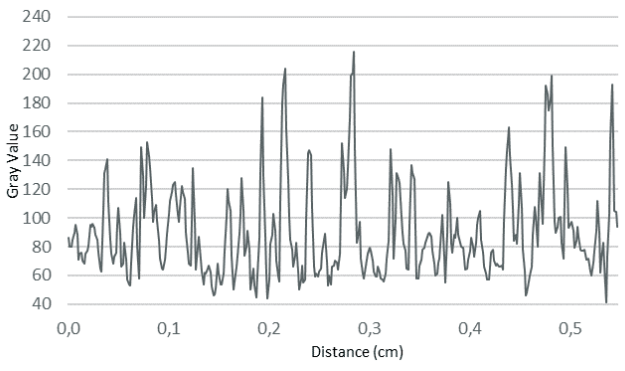

Figure 3. Representation of the gray tones in the material PET/AL/PELD

The coefficient of friction was measured in the laboratory according to ASTM 1894 method. The measuring device was SST3-XS, RDM with 
a speed control of $1 \mathrm{~mm} / \mathrm{min}$ to $1000 \mathrm{~mm} /$ $\min \pm 0,5 \%$. The working environment moved within a temperature span of $5-50^{\circ} \mathrm{C}$. The dynamic coefficient of friction is the continuous average value obtained when the film passes at a given speed over a given distance. During this test in the laboratory, the film motion velocity is $100 \mathrm{~mm} / \mathrm{min}$ in the distance of $100 \mathrm{~mm}$. The foil is pressed with a weigh of $200 \mathrm{~g}=1,96 \mathrm{~N}$. The coefficient of friction of films usually ranges between 0,2 and 1 . Tolerance is \pm 2 [5].

The materials separately show the following:

Table 4. COF value of the material before the lamination

\begin{tabular}{|l|l|c|c|}
\hline Material & Method & Standard & Value COF \\
\hline BOPP & ASTM D-1894 & ISO 8295 & 0,30 \\
\hline OPA & ASTM D-1894 & ISO 8295 & 0,29 \\
\hline PE & ASTM D-1894 & ISO 8295 & $0,17-0,22$ \\
\hline PP & ASTM D-1894 & ISO 8295 & 0,25 \\
\hline PET & ASTM D-1894 & ISO 8295 & $0,45-0,50$ \\
\hline PELD & ASTM D-1894 & ISO 8295 & $0,17-0,22$ \\
\hline
\end{tabular}

After the results obtained on samples of the material of $n=20$ measurements for each material OPA / PE, BOPP / PPmet, PET / AL / LDPE a set of variable data is obtained and the mean value of measurements whose results are shown in Table 5.

Table 5. Measurements on 20 samples for COF laminated materials

\begin{tabular}{|c|c|c|c|c|c|c|}
\hline $\mathbf{n}$ & $\begin{array}{c}\text { BOPP/ } \\
\text { PP } \\
(\mathrm{COF} \\
\text { IN) } \\
\end{array}$ & $\begin{array}{c}\text { OPA/ } \\
\text { PE } \\
\text { (COF } \\
\text { IN) }\end{array}$ & \begin{tabular}{|c|} 
PET/AL/ \\
PELD \\
(COF \\
IN) \\
\end{tabular} & $\begin{array}{c}\text { BOPP/ } \\
\text { PP } \\
\text { (COF } \\
\text { OUT) } \\
\end{array}$ & $\begin{array}{c}\text { OPA/ } \\
\text { PE } \\
\text { (COF } \\
\text { OUT) } \\
\end{array}$ & \begin{tabular}{|c|} 
PET/AL/ \\
PELD \\
(COF \\
OUT) \\
\end{tabular} \\
\hline 1 & 0,312 & 0,121 & 0,176 & 0,245 & 0,239 & 0,302 \\
\hline 2 & 0,325 & 0,153 & 0,174 & 0,252 & 0,229 & 0,229 \\
\hline 3 & 0,334 & 0,15 & 0,169 & 0,245 & 0,246 & 0,284 \\
\hline 4 & 0,299 & 0,145 & 0,172 & 0,245 & 0,244 & 0,298 \\
\hline 5 & 0,325 & 0,162 & 0,158 & 0,248 & 0,248 & 0,310 \\
\hline 6 & 0,412 & 0,123 & 0,186 & 0,256 & 0,259 & 0,315 \\
\hline 7 & 0,296 & 0,134 & 0,172 & 0,291 & 0,247 & 0,303 \\
\hline 8 & 0,310 & 0,156 & 0,174 & 0,265 & 0,256 & 0,331 \\
\hline 9 & 0,325 & 0,194 & 0,187 & 0,253 & 0,252 & 0,327 \\
\hline 10 & 0,358 & 0,185 & 0,171 & 0,248 & 0,248 & 0,324 \\
\hline 11 & \begin{tabular}{l|l}
0,378 \\
\end{tabular} & 0,162 & 0,178 & 0,244 & 0,261 & 0,223 \\
\hline 12 & 0,298 & 0,159 & 0,184 & 0,237 & 0,232 & 0,309 \\
\hline 13 & 0,289 & 0,141 & 0,177 & 0,257 & 0,241 & 0,312 \\
\hline 14 & 0,321 & 0,129 & 0,192 & 0,263 & 0,254 & 0,292 \\
\hline 15 & 0,389 & 0,138 & 0,183 & 0,253 & 0,264 & 0,287 \\
\hline 16 & 0,323 & 0,136 & 0,165 & 0,261 & 0,247 & 0,324 \\
\hline 17 & 0,329 & 0,146 & 0,162 & 0,259 & 0,249 & 0,328 \\
\hline 18 & 0,319 & 0,151 & 0,181 & 0,247 & 0,234 & 0,314 \\
\hline 19 & 0,308 & 0,149 & 0,179 & 0,241 & 0,254 & 0,321 \\
\hline
\end{tabular}

\begin{tabular}{|c|c|c|c|c|c|c|}
\hline $\mathbf{n}$ & $\begin{array}{c}\text { BOPP/ } \\
\text { PP } \\
\text { (COF } \\
\text { IN) }\end{array}$ & $\begin{array}{l}\text { OPA/ } \\
\text { PE } \\
\text { (COF } \\
\text { IN) }\end{array}$ & $\begin{array}{c}\text { PET/AL/ } \\
\text { PELD } \\
\text { (COF } \\
\text { IN) }\end{array}$ & $\begin{array}{l}\text { BOPP/ } \\
\text { PP } \\
\text { (COF } \\
\text { OUT) }\end{array}$ & $\begin{array}{l}\text { OPA/ } \\
\text { PE } \\
\text { (COF } \\
\text { OUT) }\end{array}$ & $\begin{array}{c}\text { PET/AL/ } \\
\text { PELD } \\
\text { (COF } \\
\text { OUT) }\end{array}$ \\
\hline 20 & 0,317 & 0,135 & 0,188 & 0,249 & 0,231 & 0,314 \\
\hline $\bar{x}$ & 0,328 & 0,148 & 0,176 & 0,252 & 0,246 & 0,302 \\
\hline
\end{tabular}

The arithmetic mean shows us the location of the statistical data on the numerical axis and their average. That is to say, the number is the closest to the data in theoretical and practical terms.

$$
\bar{x}=\frac{1}{n}(x 1+\ldots+x n)=\frac{1}{n} \sum_{i=1}^{n} x i
$$

The standard departure or standard deviation $(s)$ is the average mean square deviation of the numerical values of some size $\mathrm{x} 1, \mathrm{x} 2, \ldots, \mathrm{xn}$ of their arithmetic mean $\bar{x}$. The standard deviation shows how close the data is to us. Smaller the $s$, closer $\mathrm{x}$ to the data. If $s=0$, all values are the same, and $x$ equals all values.

$$
\begin{aligned}
& s^{2}=\frac{1}{n}\left[(x 1-\bar{x})^{2}+\cdots+(x \mathrm{n}-\bar{x})^{2}\right] \\
& s^{2}=\frac{1}{n} \sum_{i=1}^{n}(x i-\bar{x})^{2}
\end{aligned}
$$

In this research work, through the results of 20 measurements of the friction coefficient and after calculated average values of results, the standard deviation is presented for each material separately. The calculation shows how much the results obtained deviate from the average.

The results obtained are shown in Table 6 .

Table 6. Standard deviation for coefficient of friction according to ISO 8295

\begin{tabular}{|l|c|c|c|}
\hline $\begin{array}{l}\text { Laminate } \\
\text { material }\end{array}$ & $\begin{array}{c}\text { ISO } \\
\text { standard }\end{array}$ & $\begin{array}{c}\text { Standard devi- } \\
\text { ation COF IN }\end{array}$ & $\begin{array}{c}\text { Standard devia- } \\
\text { tion COF OUT }\end{array}$ \\
\hline BOPP/PP & ISO 8295 & 0,032 & 0,012 \\
\hline OPA/PE & ISO 8295 & 0,018 & 0,019 \\
\hline $\begin{array}{l}\mathrm{PET} / \mathrm{AL} / \\
\mathrm{PELD}\end{array}$ & ISO 8295 & 0,009 & 0,029 \\
\hline
\end{tabular}

The relative standard deviation or coefficient of variation (v) is the ratio of standard deviation and arithmetic mean $(\bar{x})$ multiplied by 100 .

$$
\begin{aligned}
& \text { coefficient of variation }(\%)=\frac{\text { standard deviation }}{\text { avarage coef ficient of friction }} \times 100 \\
& \mathrm{v}(\%)=\frac{\sigma}{\bar{x}} \mathrm{xd}
\end{aligned}
$$

The results obtained are shown in the Table 7. 
Table 7. Precision of dynamic coefficient of friction

\begin{tabular}{|l|l|l|l|l|}
\hline $\begin{array}{l}\text { Laminate ma- } \\
\text { terial (nominal } \\
\text { thickness in } \\
\boldsymbol{\mu m})\end{array}$ & $\begin{array}{l}\text { Avarage } \\
\text { coefficient of } \\
\text { friction }(\mathbf{n}=20)\end{array}$ & $\begin{array}{l}\text { Standard deviation } \\
\text { - COF (Coefficient } \\
\text { of variation) }\end{array}$ \\
\cline { 2 - 5 } & IN & OUT & IN & OUT \\
\hline $\begin{array}{l}\text { BOPP/PP } \\
(43-45)\end{array}$ & 0,328 & 0,252 & $\begin{array}{l}0,032 \\
(9,8 \%)\end{array}$ & $\begin{array}{l}0,012 \\
(4,6 \%)\end{array}$ \\
\hline $\begin{array}{l}\text { OPA/PE } \\
(90)\end{array}$ & 0,148 & 0,246 & $\begin{array}{l}0,018 \\
(12,4 \%)\end{array}$ & $\begin{array}{l}0,019 \\
(4,0 \%)\end{array}$ \\
\hline $\begin{array}{l}\text { PET/AL/PELD } \\
(97-101)\end{array}$ & 0,176 & 0,302 & $\begin{array}{l}0,009 \\
(5,0 \%)\end{array}$ & $\begin{array}{l}0,029 \\
(9,7 \%)\end{array}$ \\
\hline
\end{tabular}

Finally, the roughness of the surface of all three materials was researched, both inside and outside. The measurement was performed using TR200. The roughness of the surface is measured on the part of the sample to which the head of the device that accompanies the surface at a constant rate is placed. When the sharp needle on the head of the device collects the data it generates them and we obtain the result parameters. In this research, we measured arithmetical mean deviation of profile ( $\mathrm{Ra})$. Ra is arithmetic mean of absolute values of profile deviation (Yi) from mean within sampling length. The measurement unit $\mathrm{Ra}$ is micron $(\mu \mathrm{m})$.

$R a=\frac{1}{n} \sum_{i=l}^{n}|Y i|$

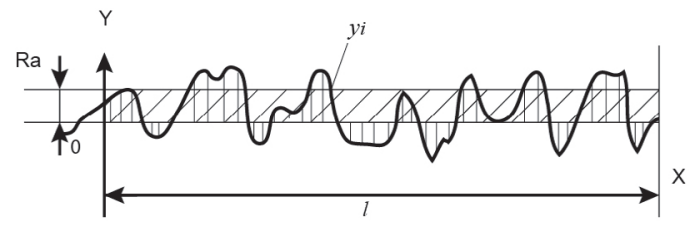

The measurement was performed for $\mathrm{n}=10$ for each material, for the three samples on the inside 10 measurements, and for the three samples on the outside of the same sample for 10 measurements. The following results are presented in Table 8 .

Table 8. Roughness of surface Ra value of laminated materials

\begin{tabular}{|l|c|c|c|c|c|c|}
\hline $\mathbf{n}$ & $\begin{array}{c}\text { BOPP/ } \\
\text { PP (Ra } \\
\text { IN) }\end{array}$ & $\begin{array}{c}\text { OPE } \\
\text { PEa } \\
\text { IN) }\end{array}$ & $\begin{array}{c}\text { PET/ } \\
\text { AL/ } \\
\text { PELD } \\
\text { (Ra IN) }\end{array}$ & $\begin{array}{c}\text { BOPP/ } \\
\text { PP } \\
\text { (Ra } \\
\text { OUT) }\end{array}$ & $\begin{array}{c}\text { OPA/ } \\
\text { PE (Ra } \\
\text { OUT) }\end{array}$ & $\begin{array}{c}\text { PET/AL/ } \\
\text { PELD } \\
\text { (Ra } \\
\text { OUT) }\end{array}$ \\
\hline 1 & 0,002 & 0,003 & 0,071 & 0,004 & 0,004 & 0,062 \\
\hline 2 & 0,004 & 0,004 & 0,008 & 0,004 & 0,004 & 0,004 \\
\hline 3 & 0,005 & 0,006 & 0,004 & 0,003 & 0,006 & 0,002 \\
\hline 4 & 0,008 & 0,001 & 0,003 & 0,002 & 0,012 & 0,005 \\
\hline 5 & 0,004 & 0,003 & 0,002 & 0,005 & 0,001 & 0,005 \\
\hline 6 & 0,005 & 0,004 & 0,002 & 0,004 & 0,004 & 0,005 \\
\hline 7 & 0,004 & 0,004 & 0,004 & 0,004 & 0,005 & 0,010 \\
\hline
\end{tabular}

\begin{tabular}{|l|c|c|c|c|c|c|}
\hline $\mathbf{n}$ & $\begin{array}{c}\text { BOPP/ } \\
\text { PP (Ra } \\
\text { IN) }\end{array}$ & $\begin{array}{c}\text { OPE (Ra } \\
\text { IN) }\end{array}$ & $\begin{array}{c}\text { PET/ } \\
\text { AL/ } \\
\text { PELD } \\
\text { (Ra IN) }\end{array}$ & $\begin{array}{c}\text { BOPP/ } \\
\text { PP } \\
\text { (Ra } \\
\text { OUT) }\end{array}$ & $\begin{array}{c}\text { OPA } / \\
\text { PEa (Ra) }\end{array}$ & $\begin{array}{c}\text { PET/AL/ } \\
\text { PELD } \\
\text { (Ra } \\
\text { OUT) }\end{array}$ \\
\hline 8 & 0,004 & 0,003 & 0,002 & 0,006 & 0,004 & 0,007 \\
\hline 9 & 0,002 & 0,005 & 0,003 & 0,007 & 0,006 & 0,008 \\
\hline 10 & 0,005 & 0,006 & 0,004 & 0,003 & 0,003 & 0,004 \\
\hline
\end{tabular}

\section{Results and discussion}

Based on the obtained results, it can be seen that migration within the material shows instability and that COF values differ.

Chart 1. shows the variability of the internal friction coefficient for the tested packaging material, where it can be seen that after the laminating the values move to BOPP / PPmet within the standard, while the values for OPA / $\mathrm{PE}$ and PET / AL / PELD laminates are slightly below 0,2 .

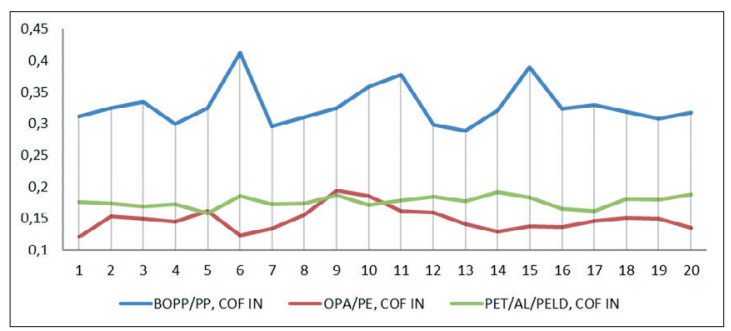

Chart 1. The internal friction coefficient of the laminate on samples of $\mathbf{n}=\mathbf{2 0}$

Variability of the external coefficient of friction for the tested packaging material shows that all the tested samples range from 0,2 to 1 as there are no values that deviate from the standard.

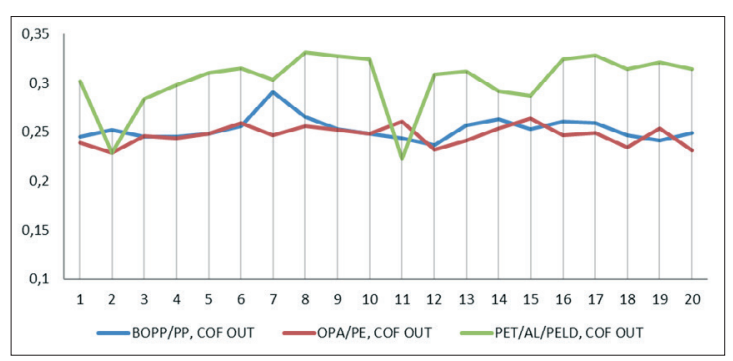

Chart 2. External friction coefficient with laminate on samples of $n=20$

The mean value was obtained as expected according to the results and showed a deviation in the internal friction coefficient only with duplex OPA / PE and triplex PET / AL / PELD. When compared to the standard deviation, we see how close the data is obtained by measuring. For ease of judgment, the characteristics of the degree of variability standard deviation was 
calculated. The slightest deviation is in OPA / $\mathrm{PE}$ laminates whose results are closest to the arithmetic mean $\bar{x}$ and is 0,13 .

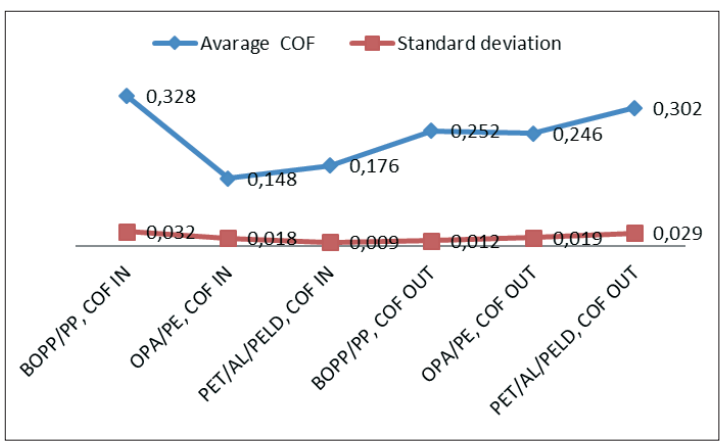

Chart 3. The mean value and standard deviation of the outer and inner coefficient of friction on laminates BOPP/PPmet, OPA/PE, PET/AL/PELD

The coefficient of variation obtained as the ratio of the arithmetic mean and the standard deviation is multiplied by 100 . The average deviation of the arithmetic mean value for the BOPP / $\mathrm{PP}$ internal friction coefficient is 0,328 or $9,8 \%$. The lowest coefficient of variation is in the OPA / PE outer coefficient of friction laminate and is $4 \%$ or 0,019 .

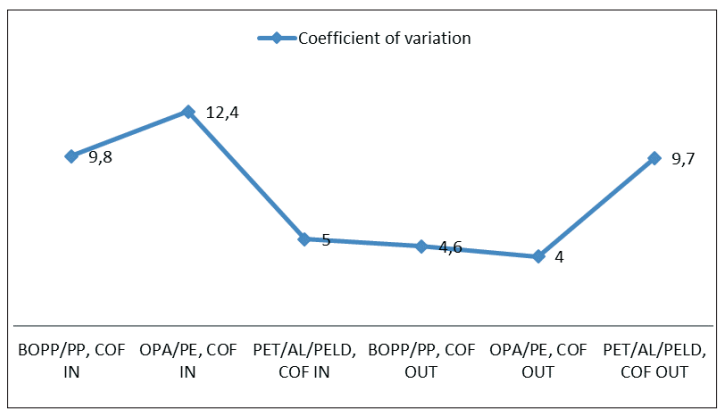

Chart 4. Coefficient of variation (\%) of outer and inner coefficient of friction on laminates BOPP/PPmet, OPA/ PE, PET/AL/PELD

Polymer laminated materials investigated in this paper show very low surface roughness, due to its exceptional smoothness and shine [11]. The roughness of the surface has a great influence on the glide of the material itself and may affect the movement of the material on the packaging machine.

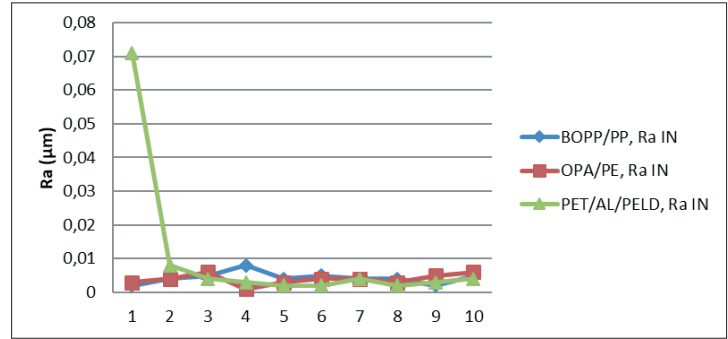

Chart 5. The roughness of the surface $(\mathrm{Ra})$ on the inner side of the laminate BOPP / PPmet, OPA / PE, PET / $\mathrm{AL} / \mathrm{PELD}$ of $\mathrm{n}=10$

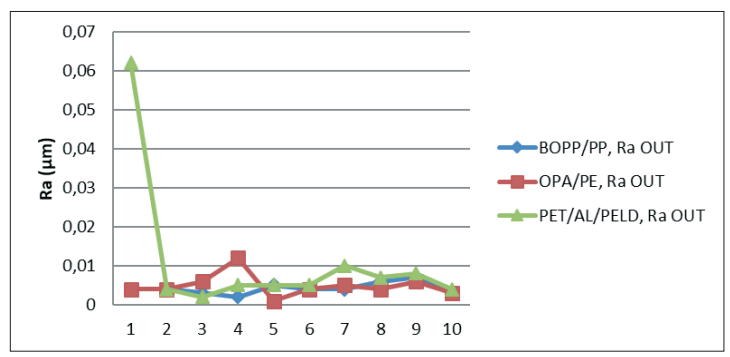

Chart 6. Roughness of the surface (Ra) on the outside of the laminate BOPP / PPmet, OPA / PE, PET / AL / PELD of $n=10$

\section{Conclusions}

By examineing the dynamic coefficient of friction polymer materials in this paper, we have obtained several conclusions. Tests and measurements of material sliding coefficient depend to a large extent on the measurement conditions and equipment at which the measurement is performed. Two surfaces of inner and outer material were measured. The results of the dynamic coefficient of friction were obtained individually and their mean value $(\bar{x})$. The mean value is visible on the indicators of their sparse or dispersion. Internal and external coefficients of friction of laminated materials are shown by the absolute dispersion measure, and that is the standard deviation $(s)$ and relative dispersion measure or coefficient of variation (v). Standard deviation as the average deviation of the original values from the arithmetic mean. Coefficient of variation as a percentage of standard deviation from the arithmetic mean.

The maximum deviation referred to the internal friction coefficient showed a duplex laminate BOPP / PPmet, which was 0,032 . While in the case of the external coefficient of friction the greatest deviation from the arithmetic medium for triplex laminate PET / AL / PELD is 0,029. The internal OPA / PE material shows 
the highest variation coefficient of $12,4 \%$, while for the same material for the external coefficient of friction the coefficient of variation is at least $4 \%$ and shows the lowest dispersion of the results.

The roughness of the surface of $\mathrm{Ra}$ indicates the very smooth surface of the material. The biggest difference is the triplex PET/AL/PELD material which shows slightly larger roughness than the other two samples. Ra values range from 0,002 to $0,008 \mu \mathrm{m}$ for the inner surface of the material. The outer surface shows values from 0,002 to $0,012 \mu \mathrm{m}$.

Considering to the presented results it is shown that due to the impact of laminating the materials themselves, and migrate Slip Additives within the material values differ. The pre-curing monomaterials exhibit certain friction coefficient values, but when materials are joined to the laminate friction coefficients are changed. The difference in these results is expected due to change in the properties of the material.

Inclusive, all materials are within permissible limits of tolerance \pm 2 of the results obtained by this research.

\section{References}

1. Selke S.E., Hernandez R.J., 2016. Packaging: Polymers in Flexible Packaging, Encyclopedia of Materials, Reference Module in Materials Science and Materials Engineering.

2. Mensitieri G., Scherillo G., Iannace S., 2013. Flexible packaging structures for high pressure treatments, Innovative Food Science \& Emerging Technologies, Volume 17, Pages 12-21.

3. Galić K., Ciković N., Berković K., 2000. Analiza ambalažnog materijala, Sveučilište u Zagrebu.

4. Sekhar J., 2018. Tunable Coefficient of friction with surface texturing in materials engineering and biological systems, Current Opinion in Chemical Engineering.

5. ISO 8295:1995. Plastic - Film and sheeting - Determination of the coefficient of friction, European standard.

6. Bates Irena, Zjakić Igor, Budimir Ivan, 2014. Assessment of the print quality parameters impact on the high-quality flexographic print visual experience, The Imaging Science Journal, Volume 63 (2), Pages 103110 .

7. Izdebska Joanna, Sabu Tomas, 2015. Printing on Polymers.

8. Jankowiak T., Rusinek A., List G., Sutter G., Abed F., 2015. Numerical analysis for optimizing the determination of dynamic friction coefficient, Tribiology International.
9. Pauše Ž., 1993. Uvod u matematičku statistiku. Školska knjiga, Zagreb.

10. Pavlović Ž., Novaković D., Cigula T., 2012. Wear analysis of the offset printing plates non - printing areas depending on exploitation. Technical Gazette 19, 3(2012), 543-548.

11. Barry A. Morris, 2017. The Science and Technology of Flexible Packaging, Multilayer Films from Resin and Process to End Use, A volume in Plastics Design Library, Pages 69-119. 
This page was left blank intentionally! 